\title{
Dimensions of Inequality in Urban and Rural Water, Sanitation and Hygiene Services in Sub-Saharan Africa
}

\author{
Odafivwotu Ohwo \\ Department of Geography and Environmental Management, \\ Niger Delta University, Wilberforce Island, Bayelsa State, Nigeria
}

\begin{abstract}
The attainment of the Sustainable Development Goals (SDGs) for water, sanitation and hygiene (WASH) requires the elimination of all forms of inequalities in WASH services. Hence, this study was aimed at the assessment of the dimensions of inequality in urban and rural WASH services in sub-Saharan Africa. This study adopted a descriptive design based on secondary data obtained from the 2015, Joint Monitoring Programme (JMP) report that contains global estimates on WASH services. The obtained data were presented in tables and analyzed using percentages. The study revealed that generally there exist inequalities in WASH services at different levels in the region and particularly between urban and rural areas. These disparities are threats toward the attainment of the SDGs for WASH in the region. To avoid these threats, all countries in the region must develop WASH policies that eliminate inequalities to WASH services, promote education and alleviate poverty; reduce corruption in the WASH sector and develop the capacity of institutions charged with WASH services with improved funding and accountability.
\end{abstract}

Keywords: Hygiene, Inequality, Rural, Sanitation, Urban, Water

\section{Introduction}

The importance of adequate WASH services for healthy living and socioeconomic development cannot be overemphasized. This prompted the inclusion of WASH services in the Millennium Development Goals (MDGs), Sustainable Development Goals (SDGs) and the declaration of the Human Right to Safe Drinking Water and Sanitation by the United Nations Assembly in 2010. The implication of this declaration is that all humans should have access to safe and affordable drinking water and sanitation services at all times. 
In spite of the achievements made so far through these global efforts, WASH services are still inadequate in sub-Saharan Africa (SSA). For example, the first global assessment report on 'safely managed' drinking water and sanitation services by the WHO and UNICEF (2017) revealed that three out of ten (30\%) people globally lacked access to safe drinking water at home, while six out of 10 (60\%) people lacked access to safely managed sanitation. This recent statistics is at variance with the figures reported in 2015 MDGs assessment on water and sanitation, where 91\% of the global population was said to have access to improved drinking water and $68 \%$ to improved sanitation (WHO \& UNICEF, 2015). The difference shows that the SDGs monitoring indicators are much more detailed and comprehensive than the MDGs. These global statistics could be misleading because they conceal the true state of affairs across regions, among countries and even within countries. Progress report indicates that in almost all nations of the world, there exist inequalities in WASH services between urban and rural areas, the rich and the poor and the marginalized and vulnerable groups (WHO \& UNICEF, 2014). These forms of inequality if not addressed adequately and promptly could pose a threat to the attainment of the SDG for water and sanitation by 2030 .

Studies have shown that WASH services are better provided in urban areas than in rural areas and among the rich, than the poor in SSA (Adams \& Smiley, 2018; Roche et al, 2017; Adams et al, 2016; WHO \& UNICEF, 2015). For example, the JMP report revealed that the percentage of the population in urban and rural areas in SSA that had piped water on premises in 2015 was 33\% and five per cent, respectively. Also, the proportion of the rural population that used surface water was $15 \%$, while it was two per cent in the urban centres. Similarly, $40 \%$ of the urban population in SSA used improved sanitation, while in the rural area it was $23 \%$. Furthermore, 32\% of the rural population practiced open defecation, while eight per cent does same in the urban centre. This shows that WASH provision is skewed in favour of the urban centres in SSA. In some cases the needs of the disabled, vulnerable groups, women and girls are not adequately met, thus exacerbating the existing inequalities in access to WASH services. Apart from the urban-rural inequalities in access to WASH services, there exist intra-urban and intra-rural disparities among the different socioeconomic groups in the respective urban and rural centres in SSA. In Zambia, access to improve water sources and sanitation by wealth quintile show that as households gets wealthier, access to improved water sources increased rapidly from $38.7 \%$ among the poorer households to $96 \%$ among the richer households; while access to improved sanitation by poorer households was $12.4 \%$ compared to $58.7 \%$ for richer households (Mulenga et al, 2017). Similarly, Pearson et al (2017) assert that the more socio-economically 
endowed rural households tend to have better access to WASH services than poorer households, which shows that there exist intra-rural inequalities.

The gap between the richest and the poorest quintiles in a region, country, urban or rural area is an important measure of inequality in WASH services. Therefore, the analysis of the trends in WASH services is important in order to assess whether disparities in access and service levels are being progressively reduced over time (WHO and UNICEF, 2015). This study is therefore aimed at revealing the dimensions of inequality in urban and rural WASH services in SSA, so as to bring to the fore the hidden realities behind the regional, sub-regional and national WASH services statistics, which are regularly presented and most often used in analysis of WASH coverage by policy makers. Revealing the inherent inequalities in WASH services in the region will better equip policy makers and major stakeholders on the development of workable intervention strategies to achieve the SDGs for WASH in sub-Saharan Africa by 2030. Figure 1 shows the countries in subSaharan Africa. Of the countries in the region, reliable data were not available for four countries (Congo, Sudan, South Sudan and Somalia), hence, the study covers 46 countries.

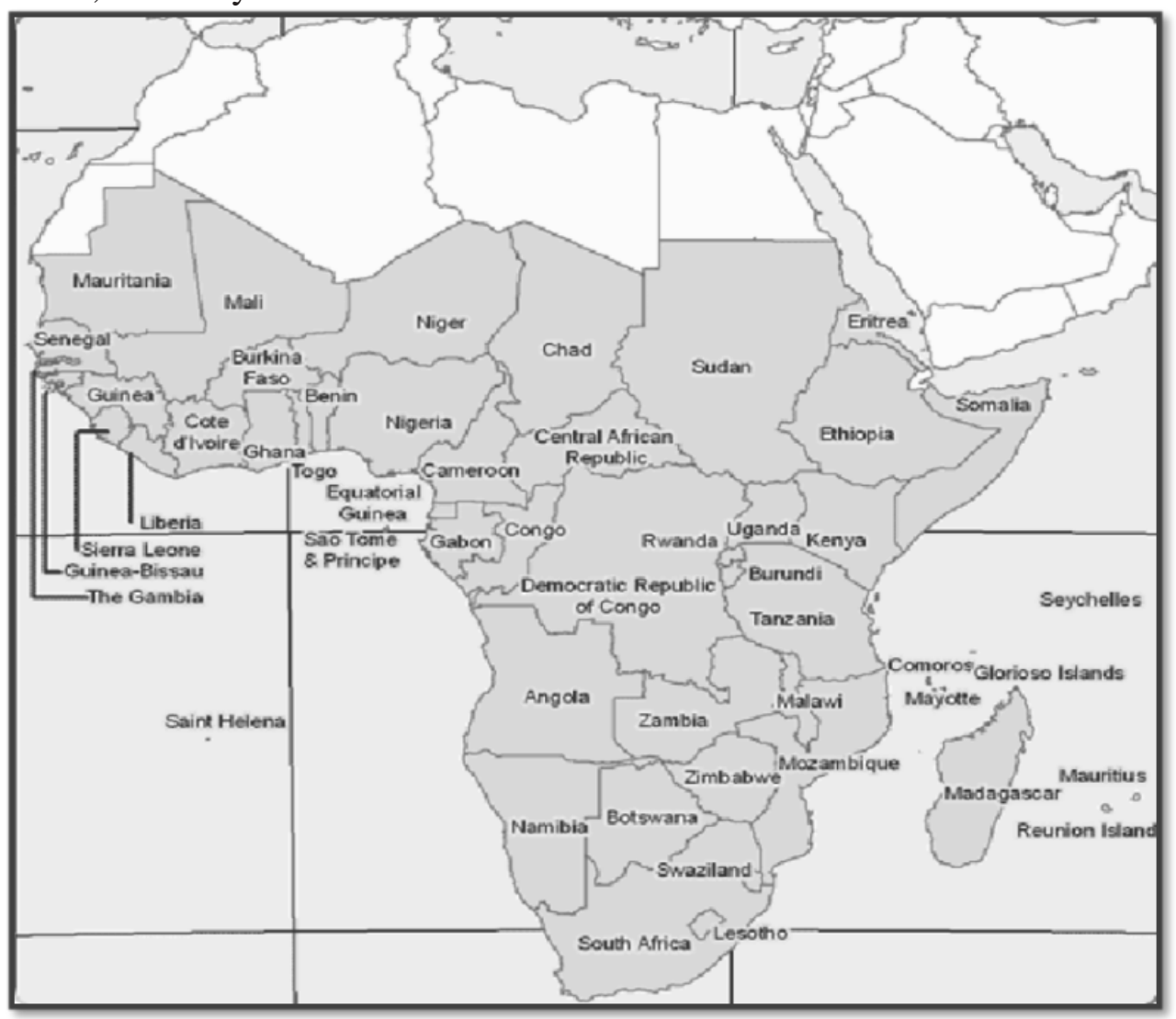

Figure 1: AfricaShowingSub-Saharan Countries 


\section{Method of Study}

The aim of this study was to assess the dimensions of inequality in urban and rural WASH services in SSA, using a descriptive design. The review was based on secondary data, which were obtained from the WHO and UNICEF (2015) Joint Monitoring Programme (JMP) that contains global estimates on used sources of drinking water, sanitation and hygiene. WASH statistics of SSA and individual countries in the region were extracted and used to assess the disparities that exist in WASH services in both urban and rural areas in the region. In order to have an in-depth insight into the disparities in WASH services in the region, other sources of secondary data on inequalities in WASH services were obtained from empirical studies in the literature, which include case studies, cross sectional studies, surveys amongst others. Some of these studies contain information on existing disparities in intra-urban and intra-rural WASH services. The data obtained from the JMP report were presented in tables and further analyzed using percentages.

\section{Urban and Rural Inequalities on Used Sources of Drinking Water}

Data from the JMP report by WHO and UNICEF (2015) show that disparities exist in urban and rural used sources of drinking water in SSA as shown in Table 1. From the table, the percentage of the population that used improved sources of drinking water was $48 \%$ in 1990 and $68 \%$ in 2015. In spite of the $20 \%$ increase in the proportion of the population that used improved sources of drinking water, the region failed to meet the MDG target for drinking water. A breakdown of this statistics show that the proportion of the urban population that used improved sources of drinking water in 1990 was $83 \%$, while it was $34 \%$ in the rural area, a difference of $49 \%$. In 2015, the proportion of the urban and rural population that used improved sources of drinking water was $87 \%$ and $56 \%$, respectively. In addition, the proportion of urban and rural population that had piped water on premises in 1990 was $43 \%$ and four per cent respectively; while in 2015, the urban and rural proportion was, respectively $33 \%$ and five per cent. Furthermore, $15 \%$ of the rural population used surface water (classified as the worst source of drinking water), while it was two per cent in the urban area. These statistics show that the proportion of people with access to improved sources of drinking water was higher in the urban area than the rural area.

However, there was steady progress in the proportion of the rural population that had access to improved sources of drinking water compared to the urban area. For example, in the rural area, four per cent of the population had piped water on premises in 1990, which increased to five per 
cent in 2015. Even though the percentage increase was very low, it was better than the urban area, where the percentage of the population fell from $43 \%$ in 1990 to $33 \%$ by 2015, a whopping $10 \%$ reduction. If the monitoring indicator for SDG 6.1 (population using safely managed drinking water services) is applied the percentage reduction could even be higher because not all classified improved sources of drinking water are safely managed. The reason for this decline is probably due to the rapid rate of urbanization and population increase in urban areas without a commensurate increase in water services (Dos Santos et al, 2017). Hence, urban water access disparities are more prevalent in informal settlements and core urban areas (Adams, 2017) that are usually poorly served by the formal water distribution system.

Table 1: Urban and Rural Estimates on Used Sources of Drinking Water in Sub-Saharan Africa

\begin{tabular}{lllll}
\hline S/N Drinking water & 1990 & 2015 & 1990 & 2015 \\
Sources & & &
\end{tabular}

$\begin{array}{clllll}\text { Urban } & \text { Rural } & \text { Urban } & \text { Rural } & \text { Total } & \text { Total } \\ \text { Pop.(\%) } & \text { Pop.(\%) } & \text { Pop.(\%) } & \text { Pop.(\%) } & \text { Pop.(\%) } & \text { Pop.(\%) }\end{array}$

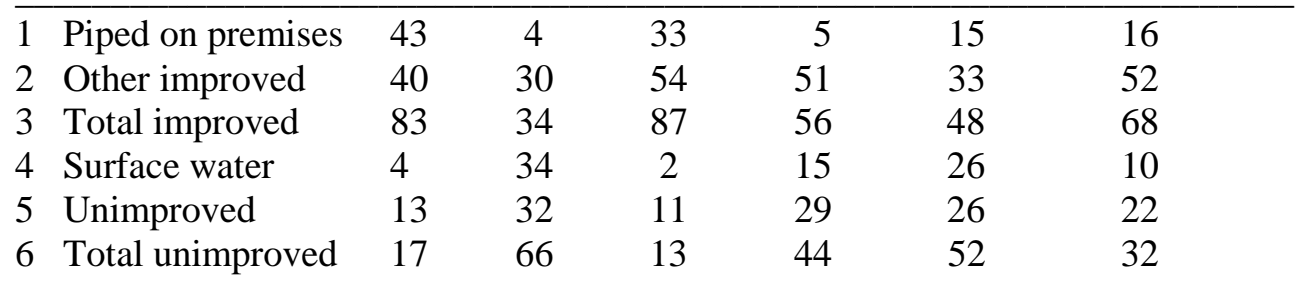

Source: Adapted from WHO and UNICEF (2015)

The statistics on urban and rural used sources of drinking water in SSA presented in Table 1 conceal the disparities that exist among and within the countries in the region. For example, WHO and UNICEF (2015) revealed that urban coverage of used sources of improved drinking water among the countries in the region range from 58-100\%, with Mauritania and Mauritius having the lowest (58\%) and highest (100\%) coverage respectively; while the rural coverage range from $28-100 \%$, with Angola having the lowest (28\%) coverage and Mauritius with the highest (100\%) coverage. In addition, $97.82 \%$ of the countries had above $70 \%$ coverage of used sources of improved drinking water in the urban area; while only $36.97 \%$ had above $70 \%$ coverage in the rural area. This shows that rural inhabitants used more of unimproved sources of drinking water (unprotected dug well, spring, river, dam, lake, pond, canal, amongst others) which are more susceptible to contamination, exposing the people to the risk of contracting waterborne 
diseases. Christenson et al (2014) assert that in Nigeria, water quality was better in the urban area than in the rural area, as the rate of water contamination was estimated to be $40 \%$ in the urban area as opposed to $60 \%$ in the rural area. The reason they gave for this water quality gap was because of the mix of the used sources of drinking water, as more people in the rural area depend more on unimproved sources of water supply compare to their urban counterparts.

A further analysis on the percentage of the urban and rural population that used the categorized 'improved sources of drinking water' (WHO \& UNICEF, 2015) shows that the percentage of the urban population that used 'piped water on premises' in 2015 range from 3-100\%, with Nigeria having the lowest (3\%) coverage, while Mauritius had the highest (100\%) coverage. In all, only $32.61 \%$ of the countries in the region had $50 \%$ and above coverage of piped water on premises in the urban area. In the rural area, the range was 0-100\%, with Mauritius having the highest (100\%) coverage, while four countries (Burkina Faso, Central Africa Republic, Eritrea and Guinea Bissau) had the lowest (0\%) coverage, which means that there was complete absence of piped water on premises in the rural areas of those countries; while only $4.35 \%$ of the countries in the region had $50 \%$ and above coverage of piped water on premises in the rural area.

More worrisome is the fact that 14 countries had reduced coverage of their urban population with piped water on premises from 1990 to 2015 as shown in Table 2. Unfortunately, this period was within the MDGs era (2000-2015) were more progress was anticipated. The highest reduction in coverage occurred in Nigeria, where the coverage reduced from $32 \%$ to three per cent, a whopping 29\% drop, while Togo had the lowest reduction from $14 \%$ to $13 \%$ within the same period. This shows that Nigeria made little or no effort to connect those not served and sustainably maintain existing water infrastructure in the urban area. The situation was fairly better in the rural area, where only two countries (Djibouti and Nigeria) experienced reduction in piped water on premises. In Djibouti the coverage level reduced from $26 \%$ in 1990 to $10 \%$ in 2015; while in Nigeria it reduced from three per cent to one per cent within the same period.The probable reason for the higher percentage reduction in coverage in the urban area is due to rural-urban migration. For example, in Nigeria, like many other countries in the region, the 1990 and 2015 population figures for urban areas were, respectively less than the rural population figures for the same period, but the urban population change (207\%) was higher than the rural population change (43\%) (Table 2), which can be explained by rural-urban migration. It should be noted that much of the improvements in access to rural drinking water sources were achieved through the installation of new boreholes and protected wells, which do not necessarily guarantee the safety and 
functionality of those water sources (Adams \& Smiley, 2018). Hence, Jiménez et al (2017) assert that rural water points tend to suffer more from periodic breakdowns and are unsustainable compared to water sources in urban areas. This assertion was substantiated by Taylor (2009) in a study in Tanzania that about one-quarter of new rural water sources stop functioning barely two years of use.

Table 2: Countries with Reduced Urban and Rural Coverage of Piped Water on Premises in Sub-Saharan Africa from 1990-2015

\begin{tabular}{llcrrrc}
\hline S/N & Country & 1990 & 2015 & 1990 & 2015 & $1990-2015$ \\
\hline & & $\begin{array}{c}\text { Urban } \\
\text { Pop.(\%) }\end{array}$ & $\begin{array}{c}\text { Urban } \\
\text { Pop.(\%) }\end{array}$ & $\begin{array}{l}\text { Urban Pop. } \\
\text { (x 1,000) }\end{array}$ & $\begin{array}{r}\text { Urban Pop. Urban Pop. } \\
\text { (x 1,000) }\end{array}$ & Change (\%) \\
& & & & & & \\
\hline 1 & DR Congo & 48 & 17 & 10,822 & 29,923 & 177 \\
2 & Eritrea & 41 & 39 & 524 & 1,550 & 196 \\
3 & Ghana & 41 & 32 & 5,266 & 14,571 & 177 \\
4 & Guinea Bissau & 14 & 11 & 285 & 876 & 207 \\
5 & Kenya & 55 & 45 & 3986 & 12,155 & 205 \\
6 & Madagascar & 22 & 16 & 2771 & 8,482 & 206 \\
7 & Malawi & 37 & 33 & 1134 & 2,769 & 144 \\
8 & Namibia & 82 & 69 & 396 & 1,124 & 184 \\
9 & Nigeria & 32 & 3 & 28,685 & 88,091 & 207 \\
10 & Sierra Leone & 16 & 11 & 1,334 & 2,528 & 90 \\
11 & Tanzania & 31 & 28 & 4,842 & 16,733 & 246 \\
12 & Togo & 14 & 13 & 1,099 & 2,868 & 161 \\
13 & Zambia & 47 & 36 & 3,060 & 6,363 & 108 \\
14 & Zimbabwe & 98 & 74 & 3,034 & 4,815 & 59 \\
& & & & & & \\
& & Rural & Rural & Rural Pop. & Rural Pop. & Rural Pop. \\
& & Pop.(\%) & Pop.(\%) & $(\mathrm{x} 1,000)$ & (x 1,000) & Change (\%) \\
15 & Djibouti & 26 & 10 & & & \\
16 & Nigeria & 3 & 1 & 66,932 & 95,432 & 43 \\
\hline
\end{tabular}

Source: Adapted from WHO and UNICEF (2015)

Apart from the general urban and rural inequalities in access to improved sources of drinking water in the region, there is pronounced disparities between the richest and the poorest quintiles in both urban and rural areas in the region. In some countries, such as Namibia, there were very large gaps between the richest and the poorest quintiles; while in GuineaBissau, there was a wide gap between the richest quintile and the others, which is known as 'top inequality'. Furthermore, in other countries such as 
Democratic Republic of Congo, the quintiles are more evenly spread with low coverage (WHO \& UNICEF, 2015).

Songsore (2000) in a study in Accra, Ghana, revealed that there was a close relationship between wealth and access to potable water. He asserts that most households surveyed in the city used piped borne water, with an uneven and erratic distribution system, especially in the low income areas and new developments in the peri-urban zone. He noted that most rich households have in-house water piping, typically connected to overhead storage containers, while the poorest and most deprived households rely mainly on water vendors, communal standpipes and other less efficient water supply sources. Therefore, the urban poor pay up to 50 times more for a litre of water than their richer counterparts, as they often have to buy their water from private vendors (UN-Water, 2010). The increase in the total number of urban dwellers without access to improved drinking water, which includes those who rely on water from carts and tankers, means that more people may be forced to pay extortionate prices for drinking water (UNICEF \& WHO (2011). This situation may worsen the plight of poor households who have to spend more money for unreliable water supply (Ohwo \& Abotutu, 2014; Lagos Water Corporation, 2013).

Another dimension of urban-rural inequalities is on the time spent to obtain water. UNICEF and WHO (2011) reported that in SSA, the time spent to collect water is higher in rural areas than in urban areas across wealth quintiles, as the need to spend more than 30 minutes on a water collection round trip is significantly more common in rural areas than in urban areas. In rural area about $20 \%$ of households spend more than 30 minutes, with over half of this population still relying on unimproved water sources. The report further stated that in the urban area the poor are much more likely to spend more time collecting water by queuing at public taps to fill their water containers than their richer counterparts who are three times more likely to have a piped water supply on premises. This situation may affect the socioeconomic life of the people (especially, rural residents and the urban poor) as the time spent collecting water could be used for other productive activities. Time spent in collecting water for the household also have a gender dimension, as in almost three quarters of households without access to piped drinking water on premises, women and girls have the primary responsibility for fetching water. Considering the distance of the water source to the residence, the task of water collection may exert significant health and social burden on women and girls. If the distance is above 30 minutes on a round trip, it may affect the quantity of water that the women and girls could collect, which could impact on the per capita water available to meet the daily needs of the household. This situation could affect good hygiene 
practice such as hand washing (Howard \& Bartram, 2003) and increase the rate of school absenteeism for girls (UNDP, 2006).

\section{Urban and Rural Inequalities on Used Sanitation and Hygiene Facilities}

The global and SSA MDG targets of $77 \%$ and $62 \%$ for sanitation were respectively missed as reported by WHO and UNICEF (2015). The report revealed that $68 \%$ of the global population and $30 \%$ of SSA population had access to improved sanitation. This represents a shortfall of nine per cent and 32\%, respectively for the global and SSA, MDG sanitation targets. Considering the shortfalls from the set targets, it is quite evident that a significant proportion of the world population (especially, in SSA) use unimproved sanitation facilities, which may pose a great challenge for the attainment of the SDG target for sanitation. In spite of the low coverage for sanitation in the region, there exist significant disparities in access to sanitation among countries in the region, between urban and rural areas, and the rich and the poor. The nature of the settlements and socioeconomic characteristics of the respective populations re-enforces the level of inequalities that exist in an area. In some areas the percentage coverage of access to improved sanitation was higher than the $30 \%$ average for the region; while it was lower in other areas.

Table 3 shows the disparities between urban and rural used sanitation facilities in the region. From the table, $24 \%$ and $30 \%$ of the total population in the region used improved sanitation facilities respectively in 1990 and 2015. By implication, $70 \%$ of the total population in the region used unimproved sanitation facilities at the end of the MDGs. Within the 30\% average total population that used improved sanitation, $40 \%$ of the urban and $23 \%$ of the rural populations used improved sanitation respectively in the region. This again shows that access to improved sanitation was better in the urban area than the rural area, just as the case with drinking water. However, the number of people that used improved sanitation increased more in the rural area by five per cent than in the urban area, which was one per cent from 1990 to 2015. Again, this could be attributable to rural-urban migration, as the case with access to piped water on premises. In 2015, the percentage of those that practice open defecation (the worst form of sanitation, and one of the clearest manifestations of extreme poverty) was 32\% and eight per cent respectively in the rural and urban areas. Similarly, the percentage of the population that stopped open defecation from 1990 to 2015 was more in the rural area (13\%) than in the urban area, which was just two per cent. Although more progress was made in the rural area during the MDGs period, however, the disparities between urban and rural areas in terms of access to 
improved sanitation is still very high and concerted effort is needed to bridge the wide gap.

Table 3: Urban and Rural Estimates on Used Sanitation Facilities in Sub-Saharan Africa

\begin{tabular}{|c|c|c|c|c|c|c|c|}
\hline \multirow[t]{2}{*}{$\mathrm{S} / \mathrm{N}$} & \multirow[t]{2}{*}{ Sanitation Facility } & \multicolumn{2}{|c|}{1990} & \multicolumn{2}{|c|}{2015} & \multirow{2}{*}{$\begin{array}{c}1990 \\
\text { Total } \\
\text { Pop.(\%) }\end{array}$} & \multirow{2}{*}{$\begin{array}{c}2015 \\
\text { Total } \\
\text { Pop. (\%) }\end{array}$} \\
\hline & & $\begin{array}{r}\text { Urban } \\
\text { Pop.(\%) }\end{array}$ & $\begin{array}{c}\text { Rural } \\
\text { Pop.(\%) }\end{array}$ & $\begin{array}{c}\text { Urban } \\
\text { Pop.(\%) }\end{array}$ & $\begin{array}{c}\text { Rural } \\
\text { Pop. (\%) }\end{array}$ & & \\
\hline 1 & Improved & 39 & 18 & 40 & 23 & 24 & 30 \\
\hline 2 & Open defecation & 10 & 45 & 8 & 32 & 36 & 23 \\
\hline 3 & Other unimproved & 21 & 29 & 18 & 34 & 26 & 27 \\
\hline 4 & Shared & 30 & 8 & 34 & 11 & 14 & 20 \\
\hline 5 & Total Unimproved & 61 & 82 & 60 & 77 & 76 & 70 \\
\hline
\end{tabular}

Source: Adapted from WHO and UNICEF (2015)

Apart from the disparities on used improved sanitation facilities in the region, there also exist significant inequalities on access to improved sanitation among the countries in SSA, as documented by WHO and UNICEF (2015). For example, the urban percentage of the population that used improved sanitation facilities among the countries in the region ranged from 18-98\%. The lowest coverage (18\%) was in Madagascar, while Réunion had the highest coverage of 98\%, with only 17 (36.96\%) of the countries having $50 \%$ and above coverage. In the rural area, the range was 398\%, with Togo having the lowest (three per cent) coverage, while Réunion had the highest (98\%) coverage, and only eight (17.39\%) of the countries had 50\% and above coverage. Although the situation was generally bad, it was worse in the rural areas of the region. The JMP data equally revealed that open defecation was practiced in both urban and rural areas in majority of the countries in the region. For example, the range of urban practice of open defecation was 0-36\%, with Mauritius, Gambia and Guinea having zero per cent, while Eritrea had 36\%. In the rural area, it ranged from 0-89\%, with Mauritius having zero per cent, while Eritrea had 89\% with 14 (30.44\%) countries having $50 \%$ and above of their rural population practicing open defecation.

In spite of the MDG target for sanitation, not much progress was recorded on the use of improve sanitation coverage among the countries in the region. In fact, in some cases there was sharp drop in coverage, as the percentage of those using improved sanitation facilities reduced significantly in both urban and rural areas (see Table 4). Table 4 revealed that eight and five countries had reduced coverage on used improved sanitation facilities in urban and rural areas, respectively from 1990-2015. The highest urban 
reduction was recorded in Eritrea, which reduced from 59\% in 1990 to 45\% in 2015; while in the rural area it was in Djibouti, which reduced from 44\% to five per cent. Within the same period (1990-2015) the practice of open defecation also increased in some of the countries in the region. In the urban area, six (13.04\%) countries recorded an increase in the practice of open defecation, with Namibia having the highest increase of $11 \%$ to $20 \%$; while in the rural area, five (10.87\%) countries had increase, with Djibouti recording the highest increase from $44 \%$ to $76 \%$ (Table 5). This is a clear indication that most countries in the region have a long way to go to achieve the SDG targets for sanitation by 2030.

Table 4: Countries with Reduced Urban and Rural Coverage on Used Improved Sanitation Facilities in Sub-Saharan Africa from1990-2015

\begin{tabular}{|c|c|c|c|c|c|c|}
\hline $\mathrm{S} / \mathrm{N}$ & Country & 1990 & 2015 & 1990 & 2015 & 1990-2015 \\
\hline & & $\begin{array}{l}\text { Urban } \\
\text { Pop.(\%) }\end{array}$ & $\begin{array}{l}\text { Urban } \\
\text { Pop.(\%) }\end{array}$ & $\begin{array}{l}\text { Urban Pop. } \\
\text { (x 1,000) }\end{array}$ & $\begin{array}{l}\text { - Urban Pop. } \\
\text { (x 1,000) }\end{array}$ & $\begin{array}{l}\text { Urban Pop. } \\
\text { Change (\%) }\end{array}$ \\
\hline 1 & DR Congo & 30 & 29 & 10,822 & 29,923 & 177 \\
\hline 2 & Djibouti & 73 & 60 & 389 & 603 & 55 \\
\hline 3 & Eritrea & 59 & 45 & 524 & 1,550 & 196 \\
\hline 4 & Namibia & 61 & 54 & 396 & 1,124 & 184 \\
\hline 5 & Nigeria & 38 & 33 & 28,685 & 88,091 & 207 \\
\hline 6 & Rwanda & 61 & 59 & 361 & 3,604 & 894 \\
\hline 7 & Zambia & 59 & 56 & 3,060 & 6,363 & 108 \\
\hline \multirow[t]{2}{*}{8} & Zimbabwe & 52 & 49 & 3,034 & 4,815 & 59 \\
\hline & & $\begin{array}{l}\text { Rural } \\
\text { Pop.(\%) }\end{array}$ & $\begin{array}{l}\text { Rural } \\
\text { Pop.(\%) }\end{array}$ & $\begin{array}{l}\text { Rural Pop. } \\
\text { (x 1,000) }\end{array}$ & $\begin{array}{l}\text { Rural Pop. } \\
\text { (x 1,000) }\end{array}$ & $\begin{array}{l}\text { Rural Pop. } \\
\text { Change (\%) }\end{array}$ \\
\hline 9 & $\begin{array}{l}\text { Central } \\
\text { African Rep. }\end{array}$ & 12 & 7 & 1,835 & 2,881 & 59 \\
\hline 10 & Djibouti & 44 & 5 & 201 & 297 & 48 \\
\hline 11 & Nigeria & 38 & 25 & 66,932 & 95,432 & 43 \\
\hline 12 & Togo & 7 & 3 & 2,689 & 4,303 & 60 \\
\hline 13 & Zimbabwe & 35 & 31 & 7,428 & 10,231 & 38 \\
\hline
\end{tabular}


Table 5: Countries with Increased Practice of Open Defecation in Urban and RuralAreas from 1990-2015

\begin{tabular}{rrrccc}
\hline S/N Countries & 1990 & 2015 & 1990 & 2015 & $1990-2015$ \\
\hline $\begin{array}{r}\text { Urban } \\
\text { Pop.(\%) }\end{array}$ & $\begin{array}{r}\text { Urban } \\
\text { Pop.(\%) }\end{array}$ & $\begin{array}{c}\text { Urban Pop. Urban Pop. } \\
(\mathrm{x} 1,000)\end{array}$ & $\begin{array}{c}\text { Urban Pop. } \\
\text { (x 1,000) }\end{array}$ & Change (\%) \\
\hline
\end{tabular}

$\begin{array}{llrrrrr}1 & \text { Burundi } & 1 & 2 & 336 & 1,298 & 286 \\ 2 & \text { Comoros } & 0 & 1 & 116 & 216 & 82 \\ 3 & \text { Namibia } & 11 & 20 & 396 & 1,124 & 184 \\ 4 & \text { Nigeria } & 7 & 15 & 28,685 & 88,091 & 207 \\ 5 & \text { Sierra Leone } & 1 & 8 & 1,334 & 2,528 & 90 \\ 6 & \text { Zimbabwe } & 1 & 2 & 3,034 & 4,815 & 59\end{array}$

\begin{tabular}{lllrrrr} 
& & $\begin{array}{c}\text { Rural } \\
\text { Pop.(\%) }\end{array}$ & \multicolumn{1}{c}{$\begin{array}{c}\text { Rural } \\
\text { Pop.(\%) }\end{array}$} & $\begin{array}{r}\text { Rural Pop. } \\
\text { (x 1,000) }\end{array}$ & $\begin{array}{l}\text { Rural Pop. } \\
\text { (x 1,000) }\end{array}$ & $\begin{array}{c}\text { Rural Pop. } \\
\text { Change (\%) }\end{array}$ \\
7 & Djibouti & 44 & 76 & 201 & 297 & 48 \\
8 & Ghana & 29 & 34 & 9,363 & 12,413 & 33 \\
9 & Nigeria & 31 & 34 & 66,932 & 95,432 & 43 \\
10 & Sierra Leone & 30 & 34 & 2,709 & 3,791 & 40 \\
11 & Tanzania & 10 & 17 & 20,643 & 35,558 & 72 \\
\hline
\end{tabular}

Source: Adapted from WHO and UNICEF (2015)

Access to improve sanitation varies in the zones/regions, between urban and rural, rich and poor, educated and uneducated amongst others. For example, in Nigeria the practice of open defecation range from 3.6-8.8\% in the six geographical zones, with the Northwest having the lowest (3.6\%) rate, while the North central zone had the highest (8.8\%) prevalence rate (Abubakar, 2017). Similarly, in Mozambique, the practice of open defecation ranged from two per cent to $75 \%$, with Niassa having the lowest (two per cent), while Zambezia had the highest (75\%) prevalent rate (WHO \& UNICEF, 2014). These wide gaps in access to improved sanitation within a country are usually masked in national averages, which make it difficult to appreciate the spatial inequalities in sanitation services. Generally, in almost all countries in SSA, access to improved sanitation is usually higher in the urban area than the rural area. However, variations still exist within an urban or rural area, due to differences in socioeconomic status of households. In Mozambique, structuring the urban and rural populations into wealth quintiles reveals another dimension of inequalities in access to improved sanitation, as the poorest $20 \%$ in urban areas have almost the same 
proportion of open defecation practice (50\%) as the average rural population (51\%). However, within the rural areas, nearly all (96\%) of the poorest quintile practices open defecation, compared with $13 \%$ of the richest quintile (WHO \& UNICEF, 2014).

Several other studies have also reported sharp disparities in access to improved sanitation between the rich and the poor in both urban and rural areas in several countries in sub-Saharan Africa. In all the studies, access to improved sanitation was better among the richer households than the poorer households and increases with increasing wealth quintile in both urban and rural areas. Generally, the richer households use more of flush toilets either in urban or rural area, compare to their poorer counterparts who mainly use unimproved sanitation facilities or practice open defecation, especially the rural poor (Mulenga et al, 2017; Roche et al, 2017). The level of education of a household head also determines the type of sanitation facility used by a household. A study in Nigeria by Abubakar (2017) shows that sewer system was used by only $0.4 \%$ of households whose heads had no education, $0.7 \%$ with primary school education, and $1.8 \%$ and $2.5 \%$ with secondary and higher education, respectively. Traditionally, in some urban and rural areas in the region, disadvantaged groups, such as women and girls, the indigenous, and the disabled bear more WASH burdens, which poses serious threat to their health (World Bank Group, 2017) and socioeconomic development.

Hygiene data for SSA was only available for 29 countries, which were obtained from 2010-2014 as documented in the JMP report, 2015. Since it was not possible to continuously monitor households' sanitation practices, the presence of hand washing facility with soap and water in a household was used as a proxy for good hygiene practice. The data shows that the total households with hand washing facility with water and soap in the surveyed countries in the region ranged from 1-47\%. The lowest value (one per cent) was recorded in Ethiopia and Liberia, while the highest percentage (47\%) was recorded in Namibia. Within this average total range, are disparities between urban and rural areas. In the urban area of the surveyed countries, households that practice good hygiene ranged from 167\%, with Liberia having the lowest (one per cent), while the highest (67\%) was recorded in Namibia, and only 13 (44.83\%) countries had $20 \%$ and above of their respective households having hand washing facilities with soap and water at home. In the rural area the range was 0-31\%, with Ethiopia and Liberia having the lowest (zero per cent), while Namibia had the highest percentage (31\%), and only four (13.79\%) countries had $20 \%$ and above coverage. This shows that hygiene practice in SSA is very poor, especially in the rural area. This situation is very serious because poor hygiene practice by households could negate benefits of using safe drinking water sources and 
adequate sanitation facilities, such as reduction in the prevalence of waterborne diseases, especially diarrhea, which is a major health burden in SSA.

\section{Causes of Inequality in WASH Services}

Several reasons have been advanced for the various dimensions of inequality in WASH services in the region. Inadequate WASH policies in some countries have accounted for the disparities in access to improved WASH services. For instance, Nigeria and other countries in the region lacked a national water supply and sanitation policy (NWSSP) for many years, which accounted for the uncoordinated and inequitable development of WASH services in the region, leading to disparities between urban and rural areas and people of different socioeconomic status. Hence, Akpabio (2012) describes Nigeria's water and sanitation policies as ad hoc mechanisms, which were prompted by international pressures and response to emergencies, as well as political efforts by successive leaders to justify existence and perceived performance. It is therefore not surprising that the colonial policy of providing public piped water to major cities at the detriment of smaller or rural areas still dominates the policy scene. For instance, a study in Lilongwe by Rusca et al (2017) assert that unequal access to water is tied to historical socio-political dynamics and power relations in Malawi. Similarly, Boakye-Ansah et al (2016) opined that intraurban inequalities in water quality may be rooted in policies that promote uneven infrastructural development. Also, the disparities that exist in urban East and West Africa were attributable to colonial policies (Hungerford \& Smiley, 2016).

Adequate provision of WASH services requires finance, which are not readily available or poorly deployed in some countries in the region, which has resulted to poor funding of WASH services by respective governments. Since the initial and routine maintenance cost of establishing these services are high, most governments in the region concentrate in the urban areas where they can benefit from economies of scale that reduce the unit costs of network infrastructure services and enjoy better cost recovery. As a result, urban areas receive better services than less agglomerated areas, such as less densely populated peri-urban areas, very small towns and rural areas (World Bank Group, 2013).

The high levels of illiteracy and poverty (especially in the rural areas, and urban slums) have also contributed to the disparities in WASH services in the region. Through their density, urban areas make public services more accessible and affordable. For exampleKariuki and Schwartz (2005) reported that on the average, a cubic metre of piped water cost $\$ 0.70-\$ 0.80$ to provide in urban areas compared with $\$ 2$ in sparsely populated areas. This implies 
that the urban poor and those in the rural areas without access to piped distribution networks and rely on informal water providers are made to pay more for the water they consume, while having the lowest consumption levels (World Bank Group, 2013). Studies have also noted that wealth and education status, determines the type of sanitation facility used by a household. Those without education are more likely to defecate in the open, and the population practicing open defecation appears to decline with increasing levels of education (Abubakar, 2017; WHO \& UNICEF, 2014).

Corruption in the WASH sector has also exacerbated inequalities in services. Corruption levels in most countries in the region is high and budget releases for development of WASH infrastructures (especially in rural areas) are either outright embezzled or mismanaged, which had led to shortfalls in projected outcomes. Although the scope of corruption varies substantially across the sector and among different countries and governance systems; estimates by the World Bank suggest that $20 \%$ to $40 \%$ of water sector finances are being lost to dishonest corrupt practices (Ohwo, 2016). In a similar vein, Ohwo (2010) asserts that corruption was one of the major reasons why the Warri Urban Water Board in Nigeria was moribund, as moneys usually budgeted for maintenance or facilities provision do not get to the actual sources the funds were meant for. In addition, inadequate power provision to power the various water infrastructures contributes to the inequalities in water provision among and within countries in the region. Studies have identified poor and erratic power supply as responsible for poor water delivery (intermittent supplies, low pressure and long hours or days without supply) in most settlements in the region (LWC, 2013; Ohwo, 2010; Efe, 2005).

\section{Bridging the Inequality Gaps in WASH Services}

The attainment of the SDGs target for water and sanitation (Goal 6) by 2030 may elude the region just as the MDGs (Goal 7c) if deliberate measures and strategies are not developed to bridge the existing inequalities in WASH services in the region. To achieve sustainable progress in dealing with the existing disparities, the major identified causes of inequalities must be addressed. Firstly, every country in the region should re-appraised their WASH policies to see how effective the policy document is in dealing with existing inequalities. Policy documents that are inadequate should be amended to meet current realities. For example Ethiopia was able to reduce the number of people practicing open defecation from $92 \%$ in 1990 to $29 \%$ in 2015, a reduction of about five times greater than the regional average (36\%-23\%) for the same period (WHO \& UNICEF, 2015) due to deliberate policy of the government to end open defecation. In addition, every WASH 
policy should address the needs of the vulnerable groups in the society (women, girls, the poor and the disabled).

Secondly, there should be an appreciable increase in funding of WASH infrastructures, especially in rural areas and peri-urban and informal settlements. No matter how well crafted a WASH policy is, without proper funding, the policy implementation will fail. It must be stated here that all funding by the government, donor agencies and other stake holders should be accounted for. Without proper accountability funds can be misappropriated through corrupt practices in the WASH sector. For proper monitoring of project executions, benefiting communities should take ownership of the projects and put pressure on the government and contractors to do the right thing. In the same manner they should also see to the sustainable management of such projects when completed.

Thirdly, there should be an aggressive programme by government to promote education, create jobs and poverty alleviation. Studies have shown that the educated and wealthy households tend to have better WASH services because they known the associated benefits and consequences and are able to afford the cost of provision and sustainably manage and maintain WASH infrastructures in their neighbourhoods. In addition, they are better able to hold their representatives and government officials to be accountable.

Fourthly, there should be capacity building for government agencies charged with the responsibilities for WASH provision to enhance their performance and service delivery. In addition, government can apply the model of Public-Private Partnership, where government efforts alone are insufficient to guaranty efficient service and where it is most appropriate. Also, appropriate technologies that are culturally acceptable, affordable and accessible should be deployed to enhance service delivery, especially in rural and informal settlements in urban areas. In all, adequate safe guards should be made for the vulnerable groups in the society. Although the nature of WASH disparities is similar in the region, however, it should be noted that the scale differs among countries and within the same country due to variations in the pattern and severity of the situation in the affected areas. Therefore, the peculiarity of each nation or area being dealt with should determine the mix of the recommendations to apply.

\section{Conclusion}

This study has revealed that there exist disparities in WASH services at different levels and scales in the region. However, the level and severity of these inequalities varies among countries and between urban and rural areas. Generally, WASH services are better in the urban areas than the rural areas, but the percentage of the population coverage from 1990-2015 appears to be decreasing in the urban area than the rural area, probably due to rural-urban 
migration. These existing inequalities may pose a serious threat towards the attainment of the SDGs targets for WASH services by 2030. In order to avoid a repeat of the failures during the MDGs period, where the region missed the water and sanitation targets, every country in the region must redouble their efforts in eliminating all forms of inequalities in WASH services and develop strategies that could lead to sustainable provision and management of WASH services for all. A proper mix of the recommendations made above could go a long way in eliminating inequalities in WASH services in the region. Attaining the SDGs targets for WASH services would manifest in improved health and socioeconomic development of the people in the region.

\section{References:}

1. Abubakar, I. R. (2017) Access to Sanitation Facilities among Nigerian Households: Determinants and Sustainability Implications, Sustainability 9, 547: 3-17

2. Adams, E.A (2017) Thirsty Slums in African Cities: Household Water Insecurity in Urban Informal Settlements of Lilongwe, Malawi, International Journal of Water Resources Development: 119. https://doi.org/10.1080/07900627.2017.1322941

3. Adams, E.A, Boateng, G.O and Amoyaw J.A (2016) Socioeconomic and Demographic Predictors of Potable Water and Sanitation Access in Ghana, Social Indicators Research 126: 673-687

4. Adams, E. A and Smiley, S. L (2018) Urban-rural Water AccessInequalities in Malawi: Implications for Monitoring the Sustainable Development Goals, Natural Resources Forum, DOI: 10.1111/1477-8947.12150

5. Akpabio, E. M. (2012) Water Supply and Sanitation Services Sector inNigeria: The Policy Trend and Practice Constraints, Working Paper Series 96, Zentrum Fur Entwicklungs-Forschung Center for Development Research, University of Bonn, Bonn, Germany.

6. Boakye-Ansah, A.S., Ferrero, G., Rusca, M., van der Zaag, P (2016)Inequalities in Microbial Contamination of Drinking Water Supplies in Urban Areas: The Case of Lilongwe, Malawi. Journal of Water and Health, 14(5): 851-863.

7. Christenson, E., Bain, R., Wright, J., Aondoakaa, S., Hossain, R., Bartram,J. (2014) Examining the Influence of Urban Definition when Assessing Relative Safety of Drinking-water in Nigeria. Science of the Total Environment, 490: 301-312.

8. Dos Santos, S., Adams, E.A., Neville, G., Wada, Y., de Sherbinin, A., Bernhardt, E.M., Adamo, S.B (2017) Urban Growth and Water 
Access in Sub-Saharan Africa: Progress, Challenges, and Emerging Research Directions, Science of the Total Environment, 607: 497-508

9. Efe, S. I. (2005) Problems of Water Supply in the Rural Communities of Delta State, Nigeria, Int. J. Ecol. Environ. Dyn. 3, 15-22

10. Howard, G and Bartram, J (2003) Domestic Water Quantity, ServiceLevel and Health, World Health Organization, Geneva

11. Hungerford, H., Smiley, S (2016) Comparing Colonial Water Provisionin British and French Africa, Journal of Historical Geography, 52: 74-83.

12. Jiménez, A., Jawara, D., LeDeunff, H., Naylor, K.A., Scharp, C. (2017)Sustainability in Practice: Experiences from Rural Water and Sanitation Services in West Africa. Sustainability, 9(3): 403

13. Karuiki, M., and J. Schwartz (2005) Small Scale Private Service Providers of Water and Electricity Supply: A Review of Incidence, Structure, Pricing and Operating Characteristics, PolicyResearch Working Paper 3727, World Bank, Washington, D.C.

14. Lagos Water Corporation (2013)Stakeholders/CSO Interaction with LSWC [Online] www.Lagoswater.org/news.php?page=51 [Accessed October 12, 2014]

15. Mulenga, J.N., Bwalya, B.B. and Kaliba-Chishimba, K. (2017) Determinants and Inequalities in Access to Improved Water Sources and Sanitation among the Zambian Households, International Journal of Development and Sustainability, Vol. 6 No. 8, pp. 746762.

16. Ohwo, O (2010)The Spatial Patterns of Water Supply and Management in Warri-Effurun Metropolis, Delta State, Nigeria. Ph.D Thesis, Department of Geography and Regional Planning, Delta State University, Abraka, Nigeria.

17. Ohwo, O (2016) Challenges of public water provision in Nigerian cities: a review, Journal of Water, Sanitation and Hygiene for Development, 06.1:1-12

18. Ohwo, O and Abotutu, A (2014) Access to Potable Water Supply in Nigerian Cities Evidence from Yenagoa Metropolis, American Journal of Water Resources, Vol. 2, No. 2: 31-36. doi: 10.12691/ajwr-2-2-1

19. Pearson, A.L., Rzotkiewicz, A., Namanya, J (2017) Perceived Access to Water: Associations with Health in Rural Uganda, American Journal of Rural Development, 5(3): 55-64.

20. Roche, R, Bain R and Cumming, O (2017) A Long Way to goEstimatesof Combined Water, Sanitation and Hygiene Coverage for 25 Sub-Saharan African Countries, PLoS ONE 12(2): e0171783.doi:10.1371/journal.pone.0171783E 
21. Rusca, M., Boakye-Ansah, A.S., Loftus, A., Ferrero, G., van der Zaag, P (2017) An Interdisciplinary Political Ecology of Drinking Water Quality, Exploring Socio-ecological Inequalities in Lilongwe's Water Supply Network, Geoforum, 84: 138-146.

22. Songsore, J (2000) Urbanization and Health in Africa: Exploring theInterconnections between Poverty, Inequality and the Burden of Disease, IWSG Working Papers 12-2000

23. Taylor, B., (2009) Management for Sustainability: Practical Lessonsfrom Three Studies on the Management of Rural Water Supply Schemes, WaterAid Tanzania, Dar es Salaam.

24. UNDP (2006) Beyond Scarcity: Power, Poverty and the Global WateCrisis, New York: United Nations

25. UNICEF and World Health Organization (2011) Drinking Water Equity,Safety and Sustainability: Thematic report on drinking water 2011

https://www.zaragoza.es/contenidos/medioambiente/onu/1194eng.pdf [Accessed, November 24, 2018)

26. UN-Water (2010) Water and Cities: Facts and figures, UN-Water DecadProgramme on Advocacy and Communication (UNW-DPAC) [Online]

http://www.un.org/waterforlifedecade/swm_cities_zaragoza_2010/pd f/_facts_and_figures_long_final_eng.pdff[Accessed November 26, 2018]

27. WHO and UNICEF (2017) Progress on Drinking Water, Sanitation andHygiene: 2017 Update and SDG Baselines, Geneva: License: CC BY-NC-SA 3.0 IGO.

28. WHO and UNICEF (2014) Progress on Drinking Water and Sanitation $2014 \quad$ Update, Geneva, Switzerland,http://www.who.int/water_sanitation report/en/

29. WHO and UNICEF (2015) Progress on Sanitation and Drinking Water-2015 Update and MDG Assessment,www.wssinfo.org/fileadmin/user .../JMP-Update-report2015_English.pdf (Accessed November 20, 2017)

30. World Bank Group (2013) Rural-Urban Disparities and DynamicsGlobal Monitoring Report [Online] siteresources.worldbank.org/

INTPROSPECTS/...GMR_2013_Chapter_2.pdf [Accessed, December 1, 2018]

31. World Bank Group (2017) Reducing Inequalities in Water Supply, Sanitation and Hygiene in the Era of the Sustainable Development Goals: Synthesis Report of the WASH Poverty Diagnostic Initiative, World Bank, Washing, DC 